\title{
Non-Synergistic UV-A Photocatalytic Degradation of Estrogens by Nano-TiO Supported on Activated Carbon
}

\author{
Suzamar M. C. Rosa, Arlene B. S. Nossol, Edson Nossol, Aldo J. G. Zarbin and \\ Patricio G. Peralta-Zamora*
} Departamento de Química, Universidade Federal do Paraná, CP 19032,
81531-980 Curitiba-PR, Brazil

\begin{abstract}
Many studies have reported significant improvements in the photocatalytic degradation capacity of $\mathrm{TiO}_{2}$ immobilized in carbonaceous materials, mainly due to a well-characterized synergistic effect. The photocatalytic degradation of the estrogens $17 \beta$-estradiol and $17 \alpha$-ethynylestradiol was evaluated using $1 \mathrm{mg} \mathrm{L}^{-1}$ aqueous solutions, employing a nanocomposite containing $\mathrm{TiO}_{2}$ and activated carbon $\left(\mathrm{TiO}_{2}-\mathrm{AC}\right)$ prepared by sol-gel technique. The synthesized materials were characterized by thermogravimetric analysis (TGA), X-ray diffraction (XRD), Raman spectroscopy and scanning electron microscopy (SEM). These techniques allowed to estimate the carbon proportion (11.4 wt. \%), the phase composition (anatase: $80.2 \%$, brookite: $14.0 \%$, and rutile: $5.8 \%$ ) and the superficial morphology. Using UV-A radiation provided by a high pressure mercury vapor lamp $(125 \mathrm{~W})$ and the synthesized photocatalysts, it was observed the almost complete removal of both estrogens in times shorter than 10 minutes. Considering the similarity between the degradation percentage of nanocomposites $\left(\mathrm{TiO}_{2}\right.$ and $\left.\mathrm{TiO}_{2}-\mathrm{AC}\right)$, no synergistic effects between $\mathrm{AC}$ and $\mathrm{TiO}_{2}$ could be assumed.
\end{abstract}

Keywords: titanium dioxide/activated carbon, nanocomposite, photocatalysis, estrogens

\section{Introduction}

Over the last two decades, many studies have demonstrated the high degradation capacity of advanced oxidation processes (AOPs). In general, homogeneous ${ }^{1}$ and heterogeneous systems ${ }^{2}$ promote fast degradation of resistant substrates, mainly due to the high oxidizing capacity of the in situ generated hydroxyl radical. ${ }^{3}$

In the context of the AOPs, heterogeneous photocatalysis occupies a prominent place, particularly when assisted by titanium dioxide. ${ }^{4}$ Many recalcitrant organic pollutants have been efficiently degraded by $\mathrm{TiO}_{2}$-photocatalysis, including azo dyes, ${ }^{5}$ pharmaceuticals ${ }^{6}$ and estrogens. ${ }^{7}$ Typically, the process is applied as slurry systems, consisting in a suspension of fine powdered $\mathrm{TiO}_{2}$. Because of these characteristics, the separation of the catalyst is expensive and time demanding, which often causes a significant reduction in the benefits of the usual mineralization of the organic substrates. ${ }^{8}$

To overcome this negative aspect, the use of immobilized photocatalysts has been proposed since $1993 .{ }^{8}$ Many

\footnotetext{
*e-mail: zamora@ufpr.br
}

chemical and physical methods have been employed to prepare $\mathrm{TiO}_{2}$ coatings on various supports, such as glass, ${ }^{9}$ silica, ${ }^{10}$ zeolite, ${ }^{11}$ among other materials. The sol-gel method and the subsequent thermal treatment usually leads to highly crystalline anatase $\mathrm{TiO}_{2},{ }^{12}$ proving to be a simple and reliable alternative for preparation of mechanically stable $\mathrm{TiO}_{2}$ films. ${ }^{13}$

Combinations between $\mathrm{TiO}_{2}$ and carbonaceous materials have been widely explored since the 1990s, with results that demonstrate significant synergistic effects that increase the catalytic activity. ${ }^{14}$ In this context, the use of activated carbon (AC) is particularly attractive, because of providing a high surface area for distribution and immobilization of $\mathrm{TiO}_{2} \cdot{ }^{14}$ According to the current literature, the synergistically enhanced photocatalytic activity observed with the use of $\mathrm{TiO}_{2}-\mathrm{AC}$ composites may be explained by the high adsorption capacity of AC and by the consequent enrichment of target molecules around the catalyst. ${ }^{14-17}$ Although the positive effect of AC on the photocatalytic efficiency of $\mathrm{TiO}_{2}$ is observed with simple mechanical mixtures, ${ }^{18}$ it is admitted that the synergetic effect can be maximized by a more intimate contact between the components, which can normally be achieved by the sol-gel technique. ${ }^{14}$ 
In general, it was observed that several studies address on the photocatalytic degradation of emerging contaminants, which represent a wide range of compounds produced naturally or synthetically (i.e., steroid hormones, pesticides, personal care products). ${ }^{19}$ Moreover, there are few reports about the degradation of estrogens employing $\mathrm{TiO}_{2}-\mathrm{AC}$. Natural (estrone-E1, 17 $\beta$-estradiol-E2 and estriol-E3) and synthetic (17 $\alpha$-ethynylestradiol-EE2) hormones are the most commonly steroid hormones found in aquatic ecosystems, mainly because of incomplete removal during wastewater treatment processes. ${ }^{20}$ Consequently, the proposal of new treatment technologies appears relevant to remove estrogens from sewage treatment plants effluents and to avoid the potential risks caused by their presence in aquatic environments.

Therefore, the aim of the present work was to investigate the photocatalytic degradation of natural (17 $\beta$-estradiol-E2) and synthetic (17 $\alpha$-ethynylestradiolEE2) estrogens in aqueous solution in presence of catalyst Degussa P25 (commercial $\mathrm{TiO}_{2}$ ), sol-gel $\mathrm{TiO}_{2}$ or $\mathrm{AC}-\mathrm{TiO}_{2}$ composite (20\% activated carbon).

\section{Experimental}

\section{Chemicals}

Commercial nanosized titanium dioxide powder, $\mathrm{TiO}_{2}$-P25 (80 wt.\% anatase/20 wt.\% rutile by X-ray diffraction, BET surface area of $50 \mathrm{~m}^{2} \mathrm{~g}^{-1}$ ), was purchased from Degussa-Hüls AG. Activated carbon (AC) with 1-2 $\mathrm{mm}$ of diameter, large pore size distribution and specific surface area of approximately $800 \mathrm{~m}^{2} \mathrm{~g}^{-1}$, was obtained from BRASILAC and previously sieved between 50 and 390 mesh. The organic solvents, methanol $\left(\mathrm{CH}_{3} \mathrm{OH}\right.$, JT Baker) and acetonitrile $\left(\mathrm{C}_{2} \mathrm{H}_{3} \mathrm{~N}\right.$, Panreac) were of HPLC grade.

Stock solutions $\left(1,000 \mathrm{mg} \mathrm{L}^{-1}\right)$ of the model substrates (17 $\beta$-estradiol-E2, Sigma-Aldrich, 98\%, and $17 \alpha$-ethynylestradiol-EE2, Sigma-Aldrich, 99\%) were prepared in acetonitrile. Working samples $\left(1 \mathrm{mg} \mathrm{L}^{-1}\right)$ were prepared in ultrapure water (Millipore system, resistivity of $18 \mathrm{M} \Omega \mathrm{cm}$ ). The chemical structure of the estrogens is shown in Figure 1.

Sodium hydroxide $\left(0.1 \mathrm{~mol} \mathrm{~L}^{-1}\right.$, Biotec $)$ and hydrochloric acid $\left(0.1 \mathrm{~mol} \mathrm{~L} \mathrm{~L}^{-1}\right.$, Qhemis) were used to adjust the $\mathrm{pH}$. Micro glass fiber filters (Macherey-Nagel) of $0.6 \mu \mathrm{m}$ pore size were used to remove remaining particles from the solutions of estrogens. The other reagents such as titanium isopropoxide, $\mathrm{Ti}\left[\mathrm{OCH}\left(\mathrm{CH}_{3}\right)_{2}\right]_{4}$, (Acros Organics) and 2-propanol (Panreac) were of analytical grade.

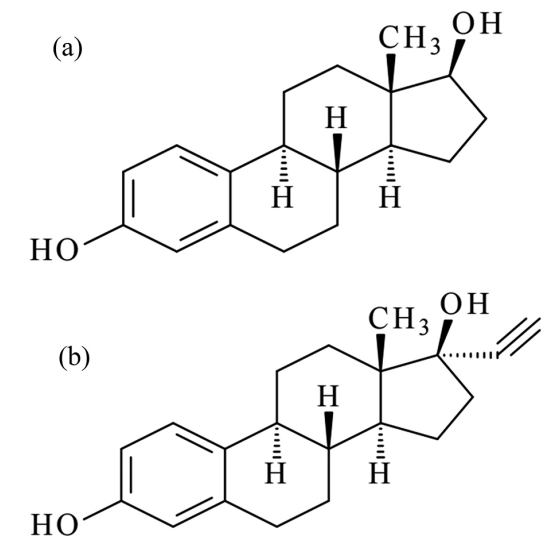

Figure 1. Chemical structure of (a) $17 \beta$-estradiol-E2 and (b) $17 \alpha$-ethynylestradiol-EE2.

\section{Synthesis of nanomaterials}

$\mathrm{TiO}_{2}$ nanoparticles were prepared at ambient temperature by the sol-gel method, according to procedures adapted from Oliveira et $a l .{ }^{21}$ (Figure S1). Step 1: in a glovebox (under argon atmosphere) a mixture containing $20 \mathrm{~mL}$ of titanium isopropoxide and $20 \mathrm{~mL}$ of 2-propanol was added dropwise to a solution containing $\mathrm{HCl}\left(120 \mathrm{~mL}, 0.2 \mathrm{~mol} \mathrm{~L}^{-1}\right)$. Step 2: to obtain the gel, the precipitate of the first step was kept on reflux system at $60{ }^{\circ} \mathrm{C}$ during $8 \mathrm{~h}$. To obtain a dry gel, the 2-propanol and water were evaporated at $80^{\circ} \mathrm{C}$. The material obtained was denominated sol-gel $\mathrm{TiO}_{2}$.

The $\mathrm{TiO}_{2}-\mathrm{AC}$ nanocomposite was obtained in a similar way, adding a weighed amount of AC (20\% of the expected mass of $\mathrm{TiO}_{2}$ ) before the formation of the precipitate (step 1, Figure S1).

\section{Characterization techniques}

Powder X-ray diffraction patterns were recorded on a Shimadzu XRD-6000 apparatus, with $\mathrm{Cu} \mathrm{K} \alpha$ radiation $(\lambda=1.5418 \AA)$ at $40 \mathrm{kV}$ and $30 \mathrm{~mA}$. The XRD patterns were collected over the $2 \theta$ range $10^{\circ}-80^{\circ}$, at a scan rate of $2^{\circ} \mathrm{min}^{-1}$. The mean crystallite size (d) was estimated based on the Scherrer's equation. ${ }^{22}$ The materials phase composition ratio was calculated using the equations proposed by Zhang and Banfield. ${ }^{23}$

Raman spectra were recorded on a Renishaw RamanImage spectrophotometer. A He-Ne laser $(\lambda=514.5 \mathrm{~nm})$ was used with $2 \mathrm{~mW}$ incidence potency over the $200-3000 \mathrm{~cm}^{-1}$ region. The relative intensities of bands D and $\mathrm{G}\left(\mathrm{I}_{\mathrm{D}} / \mathrm{I}_{\mathrm{G}}\right)$ were calculated according to Wang et al. ${ }^{24}$

The morphology and structure of the samples were verified by scanning electron microscopy using a Mira FEG-SEM (TESCAN) equipped with an energy dispersive spectrometer (EDS). 
The composition of the samples was investigated by thermogravimetric analysis (TGA) and differential scanning calorimetry (DSC), carried out on a SDT Q600 analyzer. The characterization was realized from room temperature to $1,000{ }^{\circ} \mathrm{C}$ at a heating rate of $10^{\circ} \mathrm{C} \mathrm{min}^{-1}$ under synthetic air atmosphere (White Martins).

\section{Degradation studies}

The photocatalytic degradation of the substrates was carried out in a jacketed glass cylindrical photoreactor (height: $17 \mathrm{~cm}$, internal diameter: $5.5 \mathrm{~cm}$, useful volume: $200 \mathrm{~mL}$ ), equipped with magnetic stirring and continuous refrigeration by water (temperature: $25 \pm 2{ }^{\circ} \mathrm{C}$ ). The UV-A radiation was provided by a $125 \mathrm{~W}$ low pressure mercury vapor lamp (NARDS), without the original glass bulb, immersed in the solution with the protection of a Pyrex ${ }^{\circledR}$ glass jacket. Under these conditions, the measured UV-A

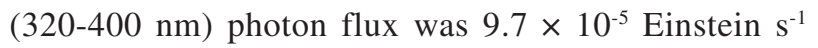
(uranyl-oxalate actinometry).

The solution containing an EE2/E2 mixture $(200 \mathrm{~mL}$, $1 \mathrm{mg} \mathrm{L}^{-1}$ ) was placed in the reactor and irradiated up to $10 \mathrm{~min}$, using photocatalyst mass and working $\mathrm{pH}$ previously optimized by factorial design. The $\mathrm{pH}$ of the samples was adjusted with aqueous solutions of $\mathrm{HCl}$ and $\mathrm{NaOH}$. Aliquots were collected at intervals of $2 \mathrm{~min}$, filtered through a micro glass fiber filter $(0.6 \mu \mathrm{m})$ to remove solid material and submitted to analytical control.

\section{Analysis}

The degradation of E2 and EE2 was monitored by high performance liquid chromatography with diode array detection (HPLC-DAD, $197 \mathrm{~nm}$ ), using a Varian 920 LC equipment. Routine determinations were carried out on a Varian Microsorb-MV100-5 C18 column $(250 \times 4.6 \mathrm{~mm}$, $5 \mu \mathrm{m})$, using a Metaguard pursuit $5 \mu \mathrm{m} \mathrm{C}-18(4.6 \mathrm{~mm})$ pre-column. The mobile phase was constituted of acetonitrile:water $(50: 50 \mathrm{v} / \mathrm{v}$, isocratic mode) and used at a flow rate of $0.8 \mathrm{~mL} \mathrm{~min}{ }^{-1}$. Analytical curves were established between 0.1 and $1 \mathrm{mg} \mathrm{L}^{-1}\left(\mathrm{n}=10, \mathrm{R}^{2}>0.99\right) .{ }^{25}$

\section{Results and Discussion}

The synthesized nanocomposite $\left(\mathrm{TiO}_{2}-\mathrm{AC}\right)$ and the raw materials (sol-gel $\mathrm{TiO}_{2}$ and $\mathrm{AC}$ ) were firstly characterized by XRD (Figure 2). As a reference, Degussa $\mathrm{P} 25 \mathrm{TiO}_{2}$ (Figure 2a) was also characterized, showing a sharper and stronger peak at $2 \theta=25.3$ corresponding to the (101) plane of the anatase structure of titania. Other less intense anatase peaks were observed at $2 \theta$ values of 36.8 (103),
37.8 (004), 38.5 (112), 48.0 (200), 54.0 (105), 55.2 (211), 62.6 (204), 68.8 (116), 70.2 (220) and 75.0 (215). Lower intensity peaks at $27.4(110), 35.9$ (101), 41.2 (111) and 56.5 (220) were assigned to the rutile phase. ${ }^{26}$

In general, it is accepted that pure anatase phase is more catalytically active than rutile..$^{27,28}$ Nevertheless, it is also recognized that anatase/rutile mixtures, as observed in Degussa $\mathrm{P} 25-\mathrm{TiO}_{2}$, shows synergistic effects, which enhances the photocatalytic activity, due to the reduction of the electron/hole recombination. ${ }^{29,30}$

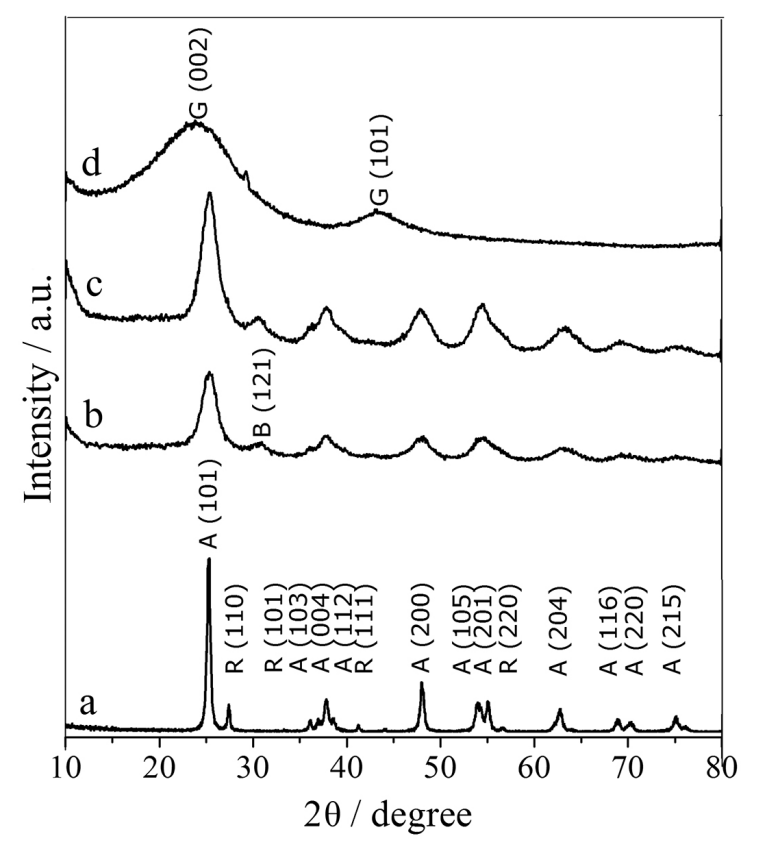

Figure 2. XRD pattern of (a) $\mathrm{TiO}_{2}-\mathrm{P} 25$; (b) sol-gel $\mathrm{TiO}_{2}$; (c) $\mathrm{TiO}_{2}-\mathrm{AC}$ and (d) raw AC.

In the X-ray diffraction patterns of sol-gel $\mathrm{TiO}_{2}$ (Figure 2b) and $\mathrm{TiO}_{2}-\mathrm{AC}$ nanocomposite (Figure 2c) anatase appears as a dominant phase $(71.9 \%$ for sol-gel $\mathrm{TiO}_{2}$ and $80.2 \%$ for $\left.\mathrm{TiO}_{2}-\mathrm{AC}\right)$. The small signal at $2 \theta=30.5$ (121) was assigned to brookite $(16.4 \%$ for sol-gel $\mathrm{TiO}_{2}$ and $14.0 \%$ for $\mathrm{TiO}_{2}$-AC) while less intense rutile peaks were observed at $2 \theta$ values of $27.4(11.7 \%$ for sol-gel $\mathrm{TiO}_{2}$ and $5.8 \%$ for $\mathrm{TiO}_{2}$-AC). A preliminary interpretation about the effect caused by the presence of brookite is a very difficult task, due to the existence of reports about its low photochemical activity, ${ }^{31}$ its "superior photoactivity" ${ }^{32}$ and the synergistic effect of anatase/ brookite mixtures. ${ }^{33}$ Recently, Di Paola et al. ${ }^{32}$ published a review about the "least known" brookite phase. According to these authors, the use of pure brookite in heterogeneous photocatalysis is not justifiable, by reason of the laborious preparation methods. In contrast, the use of mixtures of brookite with anatase and/or rutile proves to be interesting, due to a synergetic effect that hinders the electron/hole 
pair combination and improves the overall efficiency of the photochemical process.

Furthermore, broad peaks suggest smaller particle size for sol-gel $\mathrm{TiO}_{2}$ and $\mathrm{TiO}_{2}$-AC nanocomposite, with typical anatase crystallite size of approximately $10 \mathrm{~nm}$ (based on the Scherrer's equation). ${ }^{22}$ Since photocatalysis is essentially a surface phenomenon, the overall efficiency of the process tends to be significantly influenced by the particle size of the photocatalyst. ${ }^{34}$ Consequently, it is expected that the synthesized materials shows higher photocatalytic performance than the commercial Degussa $\mathrm{P} 25 \mathrm{TiO}_{2}$ (crystallite size around $40 \mathrm{~nm}$ ), even with a less favorable crystalline phase ratio.

The X-ray diffraction patterns of AC (Figure 2d) shows two broad peaks at $2 \theta=23.8$ and 43.2, which can be assigned to the characteristic (002) and (101) planes.

The Raman spectra presented on Figure 3 confirms the XRD data, demonstrating the presence of anatase (A), brookite $(\mathrm{B})$ and rutile $(\mathrm{R})$ in the synthesized materials. The $\mathrm{AC}$ and $\mathrm{TiO}_{2}-\mathrm{AC}$ spectra is characteristic of disordered carbon, showing two bands centered at approximately 1,600 (G) and 1,340 $\mathrm{cm}^{-1}(\mathrm{D})$.

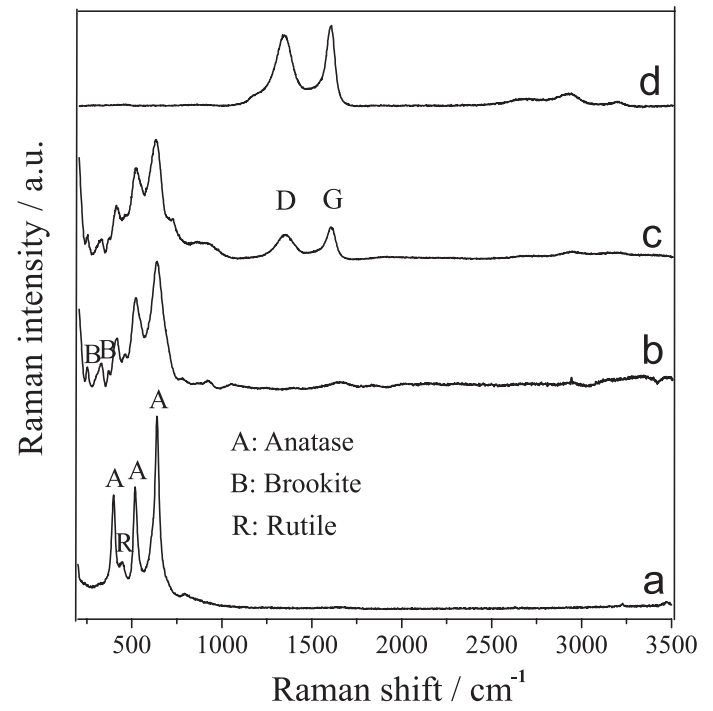

Figure 3. Raman spectra of (a) $\mathrm{TiO}_{2}-\mathrm{P} 25$; (b) sol-gel $\mathrm{TiO}_{2}$; (c) $\mathrm{TiO}_{2}-\mathrm{AC}$ and (d) raw AC.

The $\mathrm{I}_{\mathrm{D}} / \mathrm{I}_{\mathrm{G}}$ ratio is often used to evaluate the disorder of carbon materials, ${ }^{35}$ where $\mathrm{I}_{\mathrm{D}}$ represents the intensity of the $\mathrm{D}$ band (which is associated with the disorder) due to the breathing carbon bonded modes that require a defect for its activation, and $\mathrm{I}_{\mathrm{G}}$ represents the intensity of the high frequency $\mathrm{E}_{2 \mathrm{~g}}$ phonon at the Brillouin zone center ( $\mathrm{G}$ band), which is characteristic of $\mathrm{sp}^{2}$ carbon. ${ }^{36,37}$ The raw $\mathrm{AC}$ shows an estimated $\mathrm{I}_{\mathrm{D}} / \mathrm{I}_{\mathrm{G}}$ of 2.1 , which corresponds to substantially disordered carbon. Besides, the presence of $\mathrm{TiO}_{2}$ in the nanocomposite increased the estimated

value of this ratio (2.9), which suggests the introduction of significant changes in the structure of the starting material and, consequently, an intimate contact between the photocatalyst and the carbonaceous matrix.

The superficial morphology of $\mathrm{AC}, \mathrm{TiO}_{2}-\mathrm{P} 25$, sol-gel $\mathrm{TiO}_{2}$ and $\mathrm{TiO}_{2}-\mathrm{AC}$ powders was evaluated by scanning electron microscopy (SEM), and the results are shown in Figure 4. In the SEM images of activated carbon (AC) it is observed a typical porous and rough surface, while $\mathrm{TiO}_{2}-\mathrm{P} 25$ images show aggregates of spherical-shaped particles, similar to the observed by Jo and Kang. ${ }^{38}$ The images of the sol-gel $\mathrm{TiO}_{2}$ also show particle agglomeration, however, with irregular distribution and smaller dimensions than the commercial product. Finally, the SEM image of the $\mathrm{TiO}_{2}$-AC nanocomposite shows agglomerates of titanium dioxide nanoparticles covering the whole surface of the carbonaceous matrix.
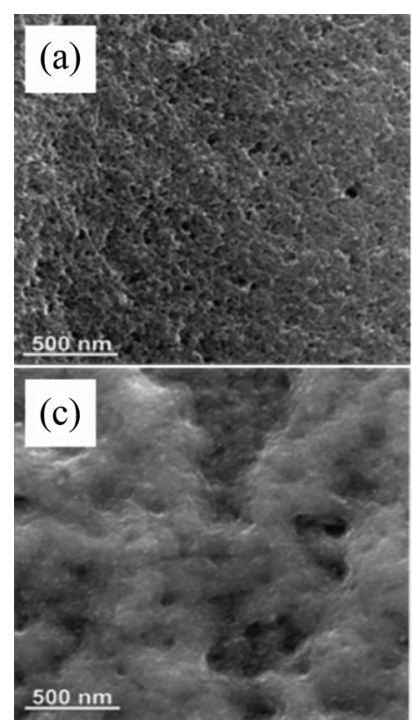

Figure 4. SEM images of (a) $\mathrm{AC}$; (b) $\mathrm{TiO}_{2}-\mathrm{P} 25$; (c) sol-gel $\mathrm{TiO}_{2}$; (d) $\mathrm{TiO}_{2}$-AC (magnification 100,000x).

The carbon mass in the synthesized nanocomposite was estimated by thermogravimetric analysis (TGA). As shown in Figure 5, when the $\mathrm{TiO}_{2}-\mathrm{AC}$ is heated from the room temperature to $1,000{ }^{\circ} \mathrm{C}$ in an air flow, the TG curve shows three-step of weight loss. The first thermal event appears between $23-154^{\circ} \mathrm{C}$ with a weight loss of $9.1 \mathrm{wt} . \%$, probably due to the endothermic removal of physically and chemically adsorbed water from the $\mathrm{TiO}_{2}$ nanoparticles. ${ }^{39,40}$ In the second step, a weight loss of $6.5 \mathrm{wt} . \%$ at the temperature range of $154-419^{\circ} \mathrm{C}$ may be associated with the decomposition of amorphous carbon layers and loss of hydroxyl groups on the $\mathrm{TiO}_{2}$ nanocrystal, ${ }^{40,41}$ and the final weight loss from 419 to $616{ }^{\circ} \mathrm{C}$ (3.9 wt.\%) refers to an exothermic process and can be attributed to the combustion of carbon ${ }^{39}$ and to the anatase to rutile phase transition. ${ }^{42}$ 
In the thermal characterization of $\mathrm{AC}$, an exothermic event was observed between 352 and $583{ }^{\circ} \mathrm{C}$, with a high weight loss, approximately $80 \%$ (Figure S2), assigned to the combustion of carbonaceous material. The TGA/DTG (derivative thermogravimetry) of nano $\mathrm{TiO}_{2}$ is shown in Figure S3.

Based on the previously exposed results, the carbon content on the synthesized nanocomposite was estimated in 11.4 wt.\%.

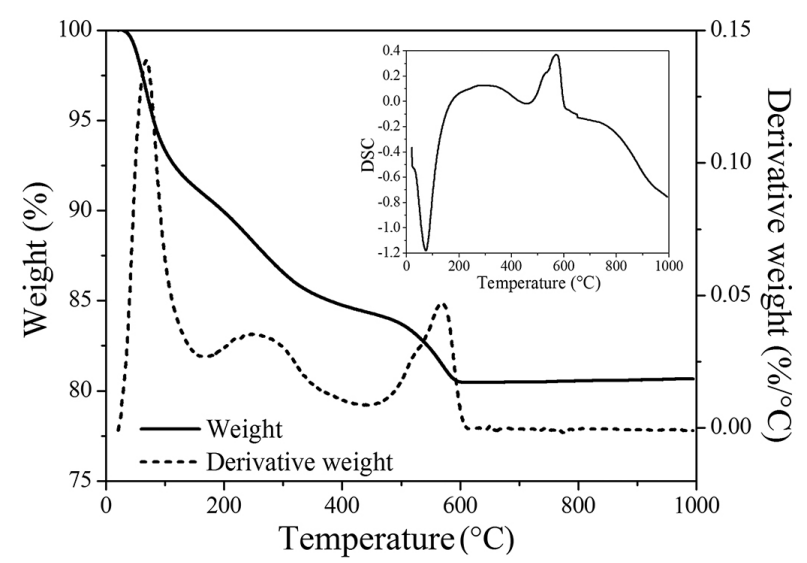

Figure 5. TGA, DTG and DSC profiles of the $\mathrm{TiO}_{2}-\mathrm{AC}$ nanocomposite.

\section{Photocatalytic activity}

Initially, the effects of two relevant operational variables ( $\mathrm{pH}$ and catalyst concentration) were evaluated by a factorial design $\left(2^{2}\right)$, using $\mathrm{TiO}_{2}$ Degussa $\mathrm{P} 25$ as a model photocatalyst, a mixture of E2 and EE2 $\left(1 \mathrm{mg} \mathrm{L}^{-1}\right)$ as substrate and photocatalytic processes assisted by artificial UV-A radiation (i.e., mercury vapor lamp). In this study (Table S1, Supplementary Information), higher degradation efficiency was observed at $\mathrm{pH} 6$ using $250 \mathrm{mg} \mathrm{L}^{-1}$ of photocatalyst, condition employed in all subsequent studies.

Under these conditions, the UV-A photolytic degradation of both estrogens was similar, reaching values of about $30 \%$ in exposure times of 10 min (Figure 6). Although many studies show a significant degradation of estrogens by direct photolysis, ${ }^{43}$ it is admitted that their contribution in photocatalytic processes is less relevant. Furthermore, many studies report the photolytic formation of reaction intermediates that can exhibit greater toxicity than the starting compounds. ${ }^{44}$

The adsorption capacity shown by $\mathrm{TiO}_{2}-\mathrm{P} 25$ and the synthesized $\mathrm{TiO}_{2}$ nanoparticles was quite similar, allowing removals lower than 5\% for both estrogens. This result is consistent with the low porosity of these materials, as highlighted by García-Muñoz et al. ${ }^{45}$ As expected, the adsorption capacity shown by the $\mathrm{TiO}_{2}-\mathrm{AC}$ nanocomposite was larger (removal near 30\% in contact time of $10 \mathrm{~min}$ ), due to the characteristic high porosity and surface area of the carbonaceous materials.

In photocatalytic processes the degradation efficiency of $\mathrm{TiO}_{2}-\mathrm{P} 25$ was superior, allowing almost complete removal of both estrogens in treatments of $4 \mathrm{~min}$. The linear correlation between $\ln \left(\mathrm{C} / \mathrm{C}_{0}\right)$ and $\mathrm{t}\left(\ln \mathrm{C} / \mathrm{C}_{0}=\mathrm{k}_{\text {appt }} \mathrm{t}\right.$, where $\mathrm{C}_{0}$ represents the initial concentration and $\mathrm{C}$ represents the concentration at a particular time, $\mathrm{t}$ ) indicates that the photocatalytic degradation follows a pseudo first-order kinetics, with apparent rate constants $\left(\mathrm{k}_{\text {app }}\right)$ of approximately $1 \mathrm{~min}^{-1}$. In the presence of $\mathrm{TiO}_{2}$ nanoparticles the degradation process was slower $\left(\mathrm{k}_{\text {app }}\right.$ ca. $\left.0.5 \mathrm{~min}^{-1}\right)$, requiring treatment times of 8 min to complete estrogen's removal.
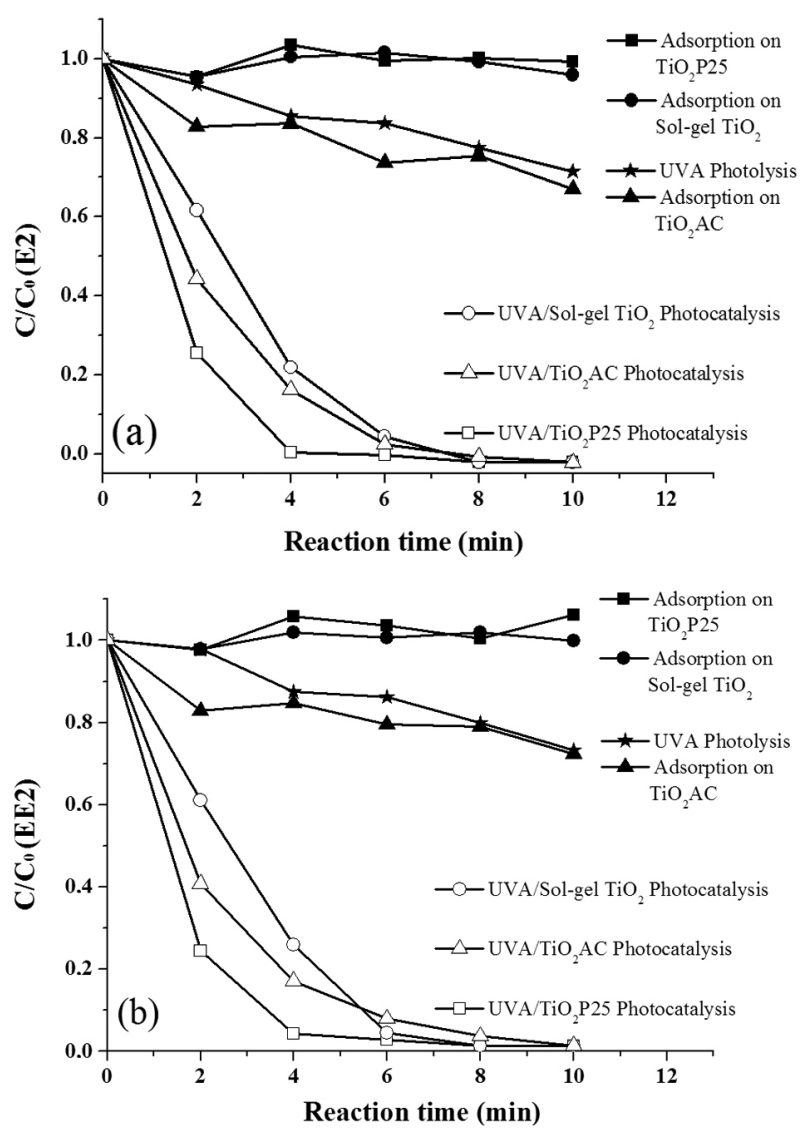

Figure 6. Removal of E2 (a) and EE2 (b) by the indicated processes (estrogens: $1 \mathrm{mg} \mathrm{L}^{-1}$, volume: $0.2 \mathrm{~L}, \mathrm{pH}: 6$, catalyst: $250 \mathrm{mg} \mathrm{L}^{-1}$ ).

The superiority of the commercial $\mathrm{TiO}_{2}-\mathrm{P} 25$, even with smaller surface area, demonstrates that the photocatalytic activity is not only dependent on the particle size, being governed by other important characteristics, such as availability of active sites. ${ }^{46} \mathrm{~A}$ complementary explanation for the higher photocatalytic activity of $\mathrm{TiO}_{2}-\mathrm{P} 25$ is based on the composition of crystalline phases. The commercial product consists in a mixture of anatase (80\%) and rutile 
(20\%), with a recognized synergistic effect, ${ }^{47,48}$ while the synthesized $\mathrm{TiO}_{2}$ nanoparticles comprise a mixture of anatase $(71.9 \%)$, brookite $(16.4 \%)$ and rutile $(11.7 \%)$, with lower photochemical activity.

The $\mathrm{AC}$ presence in the nanocomposite containing $\mathrm{TiO}_{2}$ nanoparticles causes a slight increase in the degradation capacity of the photocatalytic process $\left(\mathrm{k}_{\text {app }}\right.$ ca. $\left.0.6 \mathrm{~min}^{-1}\right)$. However, due to the higher adsorption capacity introduced by $\mathrm{AC}$, this effect cannot be considered as synergistic.

This result disagrees with many reports that describe an important synergistic effect between these components. ${ }^{8,14,45,49,50}$ Although there is a consensus on this synergistic effect, assuming that the presence of $\mathrm{AC}$ favors the approximation between substrate and photocatalyst, there are additional arguments that suggest a much more complex effect. According to Cordero et al. ${ }^{51}$ the differences in the photoactivity of $\mathrm{TiO}_{2}$ depends on the physicochemical properties of activated carbons, particularly the existence of active sites on their surface. In studies involving the degradation of 4-chlorophenol it was observed that L-type AC can induce beneficial or unfavorable effects on the $\mathrm{TiO}_{2}$ activity, depending on the presence of organic functional groups (i.e., carboxylic acid groups) that can transfer electronic density to the $\mathrm{TiO}_{2}$, thus inhibiting the recombination process.

According to observations carried out by Asenjo et al..$^{52}$ the apparent synergy between the activated carbon and $\mathrm{TiO}_{2}$ particles, claimed by several authors, is resulting from an incorrect use of the first-order form of the LangmuirHinshelwood (LH) equation. In studies involving the photocatalytic degradation of phenol, the authors showed that the use of the extended form of the $\mathrm{LH}$ equation demonstrates that the synergy is only apparent.

Finally, it is important to remark that many studies do not show adequate experimental controls in order to verify, for instance, the contribution of concomitant processes such as photolysis and adsorption. Furthermore, some studies compare the photocatalytic efficiency of $\mathrm{TiO}_{2} / \mathrm{AC}$ and pure $\mathrm{TiO}_{2}$ using the same mass of $\mathrm{TiO}_{2}$, while others may use the same overall mass. ${ }^{14}$

\section{Conclusions}

Sol-gel $\mathrm{TiO}_{2}$ and $\mathrm{TiO}_{2}$-AC nanocomposite were prepared by sol-gel methods. Both materials showed high degradation efficiency of E2 and EE2 estrogens, allowing removal greater than $90 \%$ at reaction times of 6 min. Commercial $\mathrm{TiO}_{2}-\mathrm{P} 25$ showed higher degradation efficiency than the synthesized sol-gel $\mathrm{TiO}_{2}$, probably because of its more favorable anatase/rutile ratio. Under the conditions of this study, no synergistic effect was observed.

\section{Supplementary Information}

Supplementary data are available free of charge at http://jbcs.sbq.org.br as PDF file.

\section{Acknowledgments}

Financial support from CNPq, CAPES, NENNAM (Pronex F. Araucária/CNPq) and Fundação Araucária is gratefully acknowledged.

\section{References}

1. Babuponnusami, A.; Muthukumar, K.; J. Environ. Chem. Eng. 2014, 2, 557.

2. Fujishima, A.; Zhang, X.; Tryk, D. A.; Int. J. Hydrogen Energy 2007, 32, 2664.

3. Loaiza-Ambuludi, S.; Panizza, M.; Oturan, N.; Oturan, M. A.; Catal. Today 2014, 224, 29.

4. Nakata, K.; Fujishima, A.; J. Photochem. Photobiol., C 2012, 13, 169 .

5. Bianchi, C. L.; Colombo, E.; Gatto, S.; Stucchi, M.; Cerrato, G.; Morandi, S.; Capucci, V.; J. Photochem. Photobiol., A 2014, 280, 27.

6. De la Cruz, N.; Dantas, R. F.; Giménez, J.; Esplugas, S.; Appl. Catal., B 2013, 130-131, 249.

7. Coleman, H. M.; Abdullah, M. I.; Eggins, B. R.; Palmer, F. L.; Appl. Catal., B 2005, 55, 23.

8. Shan, A. Y.; Ghazi, T. I. M.; Rashid, S. A.; Appl. Catal., A 2010, $389,1$.

9. Shen, C.; Wang, Y. J.; Xu, J. H.; Luo, G. S.; Chem. Eng. J. 2012, 209, 478 .

10. Nakano, R.; Chand, R.; Obuchi, E.; Katoh, K.; Nakano, K.; Chem. Eng. J. 2011, 260, 176.

11. Amereh, E.; Afshar, S.; Mater. Chem. Phys. 2010, 120, 356.

12. Hu, C.; Duo, S.; Liu, T.; Xiang, J.; Li, M.; Appl. Surf. Sci. 2011, 257, 3697.

13. Panniello, A.; Curri, M. L.; Diso, D.; Licciulli, A.; Locaputo, V.; Agostiano, A.; Comparelli, R.; Mascolo, G.; Appl. Catal., B 2012, 190, 122.

14. Leary, R.; Westwood, A.; Carbon 2011, 49, 741.

15. Gao, B.; Yap, P. S.; Lim, T. M.; Lim, T. T.; Chem. Eng. J. 2011, 171, 1098.

16. Ravichandran, L.; Selvam, K.; Swaminathan, M.; J. Mol. Catal. A: Chem. 2010, 317, 89.

17. Gu, L.; Chen, Z.; Sun, C.; Wei, B.; Yu, X.; Desalination 2010 , 263, 107.

18. Silva, C. G.; Wang, W.; Faria, J. L.; J. Photochem. Photobiol., A 2006, 181, 314.

19. Luo, Y.; Guo, W.; Ngo, H. H.; Nghiem, L. D.; Hai, F. I.; Zhang, J.; Liang, S.; Wang, X. C.; Sci. Total Environ. 2014, 473-474, 619. 
20. Silva, C. P.; Otero, M.; Esteves, V.; Environ. Pollut. 2012, 38, 165.

21. Oliveira, M. M.; Schnitzler, D. C.; Zarbin, A. J. G.; Chem. Mater. 2003, 15, 1903.

22. Mandal, S. S.; Bhattacharyya, A. J.; Talanta 2010, 82, 876.

23. Zhang, H.; Banfield, J. F.; J. Phys. Chem. B 2000, 104, 3481.

24. Wang, Z.; Lu, Z.; Huang, Y.; Xue, R.; Huang, X.; Chen, L.; J. Appl. Phys. 1997, 82, 5705.

25. Marinho, B. A.; de Liz, M. V.; Lopes Tiburtius, E. R.; Nagata, N.; Peralta-Zamora, P.; Photochem. Photobiol. Sci. 2013, 12, 678.

26. Venkatachalam, S.; Hayashi, H.; Ebina, T.; Nanjo, H.; Optoelectronics - Advanced Materials and Devices; Pyshkin, S., ed.; InTech: Rijeka, 2013, ch. 5.

27. Aruldoss, U.; Kennedy, L. J.; Judith Vijaya, J.; Sekaran, G.; J. Colloid Interface Sci. 2011, 355, 204.

28. Hofer, M.; Penner, D.; J. Eur. Ceram. Soc. 2011, 31, 2887.

29. van der Meulen, T.; Mattson, A.; Österlund, L.; J. Catal. 2007, $251,131$.

30. Liao, J.; Luo, R.; Li, Y. B.; Zhang, J.; Mater. Sci. Semicond. Process. 2013, 16, 2032.

31. Zhang, J.; Yan, S.; Fu, L.; Wang, F.; Yuan, M.; Luo, G.; Xu, Q.; Wang, X.; Li, C.; Chin. J. Catal. 2011, 32, 983.

32. Di Paola, A.; Bellardita, M.; Palmisano, L.; Catalyst 2013, 3, 36.

33. Yu, J. C.; Zhang, L.; Yu, J.; Chem. Mater. 2002, 14, 4647.

34. Alzamani, M.; Shokuhfar, A.; Eghdam, E.; Mastali, S.; Prog. Nat. Sci. 2013, 23, 77.

35. Tai, F. C.; Lee, S. C.; Wei, C. H.; Tyan, S. L.; Mater. Trans. 2006, 47, 1847.

36. Cançado, L. G.; Jorio, A.; Ferreira, E. H. M.; Stavale, F.;
Achete, C. A.; Capaz, R. B.; Moutinho, M. V. O.; Lombardo, A.; Kulmala, T. S.; Ferrari, A. C.; Nano Lett. 2011, 11, 3190.

37. Ferrari, A. C.; Basko, D. M.; Nat. Nanotechnol. 2013, 8, 235.

38. Jo, W.-K.; Kang, H.-J.; Mater. Chem. Phys. 2013, 143, 247.

39. Gundogdu, A.; Duran, C.; Senturk, H. B.; Soylak, M.; Imamoglu, M.; Onal, Y.; J. Anal. Appl. Pyrolysis 2013, 104, 249.

40. Xia, T.; Zhang, W.; Wang, Z.; Zhang, Y.; Song, X.; Murowchick, J.; Battaglia, V.; Liu, G.; Chen, X.; Nano Energy 2014, 6, 109.

41. Hu, Y.; Tsai, H. L.; Huang, C. L.; J. Eur. Ceram. Soc. 2003, 23, 691.

42. Liu, X.; Powder Technol. 2012, 224, 287.

43. Li Puma, G.; Puddu, V.; Tsang, H. K.; Gora, A.; Toepfer, B.; Appl. Catal., B 2010, 99, 388.

44. Chowdhury, R. R.; Charpentier, P. A.; Ray, M. B.; J. Photochem. Photobiol., A 2011, 219, 67.

45. García-Munõz, P.; Carbajo, J.; Faraldos, M.; Bahamonde, A.; J. Photochem. Photobiol., A 2014, 287, 8.

46. Carp, O.; Huisman, C. L.; Reller, A.; Prog. Solid State Chem. 2004, 32, 33.

47. Tian, G.; Fu, H.; Jing, L.; Tian, C.; J. Hazard. Mater. 2009, 161, 1122.

48. Li, G.; Gray, K. A.; Chem. Phys. 2007, 339, 173.

49. Rivera-Utrilla, J.; Sánchez-Polo, M.; Abdel daiem, M. M.; Ocampo-Pérez, R.; Appl. Catal., B 2012, 126, 100.

50. Kavitha, R.; Devi, L. G.; J. Environ. Chem. Eng. 2014, $2,857$.

51. Cordero, T.; Duchamp, C.; Chovelon, J. M.; Ferronato, C.; Matos, J.; J. Photochem. Photobiol., A 2007, 191, 122.

52. Asenjo, N. G.; Santamaría, R.; Blanco, C.; Granda, M.; Álvarez, P.; Menéndez, R.; Carbon 2013, 55, 62. 